\title{
Association of a perianal stabilization device with cesarean section rate: A prospective observational study
}

\author{
Van R Bohman ${ }^{1 *}$, Debbie T Pavlica ${ }^{2}$ and Seth R Bohman ${ }^{3}$ \\ ${ }^{1}$ University of Nevada School of Medicine, USA \\ ${ }^{2}$ Dignity Health System, USA \\ ${ }^{3}$ Tauro University, USA
}

\begin{abstract}
Background: Cesarean childbirth remains the most frequent surgical procedure in the United States. A small, randomized controlled trial documented that a device originally designed to reduce the incidence of post-partum hemorrhoids and also appeared to reduce the incidence of cesarean delivery.

Objective: The aim of this study was to evaluate the effectiveness of the Labor Guard ${ }^{\mathrm{TM}}$ perianal stabilizer in a larger and more routine clinical practice setting in which multiple obstetricians took part.

Study Design: This was an observational, prospective, cohort study in which consecutive patients who presented during a 90 -day period to the Labor and Delivery unit at Dignity Health St. Rose Hospital, Siena Campus, located in Henderson, Nevada, USA were offered the Labor Guard ${ }^{\mathrm{TM}}$ device. Patients only became eligible upon reaching $8-10 \mathrm{~cm}$ dilation.

Results: Among the 799 women were admitted to the Labor and Delivery department during the study period, 500 patients met the inclusion criteria and were offered the device. Of those patients, 227 women (45\%) were willing to use the Labor Guard ${ }^{\mathrm{TM}}$ device and became the investigational group, while 273 women (55\%) declined and became the control group. The cesarean rate for patients who chose to use the Labor Guard ${ }^{\mathrm{TM}}$ product was $4 / 227$ (1.8\%) compared to $35 / 273$ (12.8\%) for control subjects. The incidence of cesarean childbirth among primigravid patients that reached the transition phase of labor was $4 / 97$ (4.1\%) for intervention patients and 28/106 (26.4\%) for control subjects. The Labor Guard ${ }^{\mathrm{TM}}$ device and control groups were similar in terms of age, weight and ethnicity.
\end{abstract}

Conclusion: This study demonstrated a statistically and clinically significant decrease in the cesarean section rate $(1.8 \%$ vs. $13.6 \%$ OR $8.7 ; 95 \%$ CI $3.07,24.92, \mathrm{p}<$ 0.001) when comparing women who chose to use the Labor Guard ${ }^{\mathrm{TM}}$ stabilizer and those who did not.

Trial Registration: Clinical Trials Registry NCT02562547.

\section{Introduction}

According to the CDC, 3.79 million women gave birth in the United States in 2018 with a total cost of labor and delivery care of over $\$ 17$ billion [1,2]. Childbirth remains the most common reason for hospitalization of females in the United States. Cesarean sections (C-sections) made up 1.2 million of these births (31.9\%) and remain the most frequent operating room procedure in the United States [3].

There are numerous factors that influence the decision to proceed with cesarean birth after the onset of labor. Second stage arrest is one major contributor to the cesarean section rate.

The Labor Guard ${ }^{\text {mx }}$ device was originally designed and marketed as the "Hem-Avert" product with an approved indication for helping reduce the occurrence of external hemorrhoids during vaginal childbirth. The intervention is currently cleared as a Class II medical device in accordance with FDA regulation 21 CFR 801.109. The device is applied to the perianal tissue when a woman reaches $8-10 \mathrm{~cm}$ dilation and provides external counter-pressure support of perianal and perineal tissue (Figure 1). A small randomized controlled trial (RCT) carried out at by a single obstetric provider/investigator at Niagara Hospital in New York State demonstrated a clinically and statistically significant reduction in cesarean births (control $40 \%$ vs. Hem-Avert 13\%) with application of the device at onset of the second stage of labor.

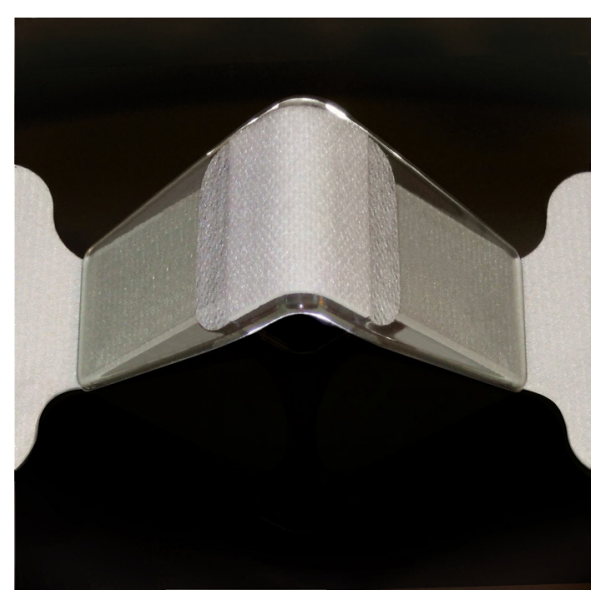

Figure 1. Components of Labor Guard ${ }^{\mathrm{TM}}$ device

*Correspondence to: Van R Bohman, 3001 W Horizon Ridge Parkway, Henderson, Nevada 89052, USA, E-mail: vanbohman@gmail.com

Key words: cesarean, perianal stabilizer, pelvic floor, Labor Guard ${ }^{\mathrm{T \mu}}$

Received: April 08, 2020; Accepted: May 13, 2020; Published: May 18, 2020 
The putative mechanism of action is not completely elucidated, but it has been proposed that the mechanism of action is related to the application of pressure to the perianal region, perineum and posterior pelvic floor. This may elicit a reflex adjustment of pelvic floor and perineal muscle tone and/or provide tactile feedback to the parturient during the second stage that improves expulsive efforts.

The objective of this study was to confirm the findings of the small RCT (98 patients) and improve the generalizability of the findings by conducting a trial with a group of community obstetric providers in a larger and more routine clinical practice setting.

\section{Methods}

This prospective, observational study met the guidelines of the US Food and Drug Administration in 21 CFR Section 812.2 for a nonsignificant risk study. The study was conducted at Dignity Health St. Rose, Siena Campus, utilizing the Hem-Avert (Labor Guard ${ }^{\mathrm{ix}}$ ) device with the approval of the Institutional Review Board (IRB), approval (DH-SR-S-01). The study was registered on Clinical Trials.Gov as NCT02562547.

Dignity Health St. Rose-Siena Campus (Henderson, NV, USA) is a 230 bed hospital that is part of the nation's fifth largest health care system. The Labor and Delivery (L \& D) unit delivers approximately 3,300 babies annually. A total of 53 OBGYN physicians delivered one or more parturients who consented to have their data included in the study. The Dignity Health IRB determined that written informed consent was not required for this study, as the intervention device was previously FDA approved for hemorrhoid prevention in the second stage of labor. All obstetric nursing staff and physicians were trained within 10 days prior to the study's start date and throughout the course of the study, as needed.

\section{Description of the intervention}

The Labor Guard ${ }^{\mathrm{Ta}}$ perianal stabilizer (Stetrix Inc., Bartlett, TN USA) is a single-use device that is supplied in a gamma-sterilized peel pouch. The device consists of three components: a rigid polymer base manufactured from medical grade polycarbonate; a centrally located cushioning pad; and two lateral "hook and loop" fastener adhesive strips (Figure 1). The device is applied when the parturient has reached 8-10 centimeters of cervical dilation. The mating strips are used to keep the device securely in place during the second stage of labor (Figure 2).

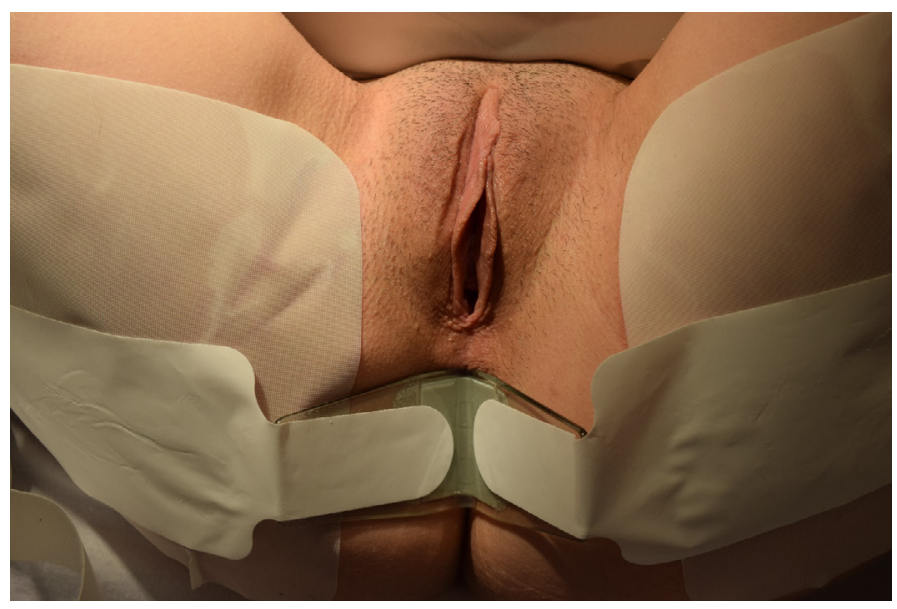

Figure 2. Placement of Labor Guard ${ }^{\mathrm{TM}}$ device
Patients were only eligible to use the device once they reached the second stage of labor; therefore, the primary outcome was a comparison of the cesarean delivery rates between those subjects who agreed to utilize the perianal stabilization device once reaching the second stage of labor and those patients who reached $8-10 \mathrm{~cm}$ dilation but did not utilize this device. Data on episiotomies and perineal lacerations were collected as a secondary outcome.

\section{Study setting}

\section{Study design}

During the 90-day period between April 1, 2015 and June 30, 2015 , a single-site, prospective, observational study was conducted to determine if use of the perianal stabilizer would be associated with a reduction in the frequency of cesarean delivery for those women who had reached 8-10 centimeters of cervical dilation. During the study period, all women who were admitted to the L \& D unit and who had no contraindication for vaginal delivery were approached by a research associate or nurse about participation in the study. Women who agreed to participate were given an opportunity to use the perianal stabilization device if they reached $8-10 \mathrm{~cm}$ dilation. Those who had the device applied were considered the intervention group. The control group consisted of all women who reached $8-10 \mathrm{~cm}$ dilation and declined to use the device, but agreed to allow their data to be used for comparison.

\section{Eligibility}

Inclusion criteria: All laboring patients were eligible for study inclusion once they reached $8-10 \mathrm{~cm}$ cervical dilation.

Exclusion criteria: Patients admitted for previously scheduled cesarean delivery were excluded. Additional exclusion criteria for patients in active labor included: failure to progress to $8 \mathrm{~cm}$ dilation; precipitous labor (i.e. precluding an appropriate consent process) or fetal or maternal contraindications to continuing a trial of labor prior to reaching full dilation.

Excluded from all analyses were 5 patients for whom demographic data was unavailable due to failure to match the study data record with a hospital medical record number.

\section{Statistical analysis}

Analysis was carried out on an Intention to Treat basis. Specifically, if the product packaging was opened, that patient was allocated to the intervention group. Descriptive summaries were provided for the baseline and delivery variables. Numeric descriptive measures included the $\mathrm{n}$ (observed values), mean, standard deviation, median, minimum and maximum. Categorical variables were summarized using the number and percentage of subjects at each level of the variables. The homogeneity of the distribution of categorical variables in the inclusion (Labor Guard $^{\text {Th }}$ perianal stabilization) and control (no Labor Guard ${ }^{\text {mox }}$ subjects) were assessed using Likelihood Ratio Chi-Square tests. The Wilcoxon Rank-Sum test was used to evaluate whether numeric variables had the same location (e.g. median). Pre-delivery and delivery variables were both reported. A p-value of 0.05 on a two-sided test was considered statistically significant. The study included only one primary hypothesis; therefore, there were no adjustments for multiplicity of testing.

The primary hypothesis was evaluated using two analytic approaches. First, a Likelihood Ratio Chi-Square test was used to assess the primary hypothesis without adjustment. The risk of the perianal stabilization patients undergoing cesarean section relative to the control 
patients was reported along with the $95 \%$ confidence interval based on the logit variance estimate.

In order to minimize the impact of potential confounding due to the non-randomized subject assignment, the association of the C-Section rate and use of perianal stabilization was analyzed using propensity scoring to stratify the patients; then, the primary hypothesis and relative risk were calculated using the stratified data. Several variables had missing values ( 2 subjects were missing prior obstetric history, 7 subjects were missing age, and 42 subjects did not have baseline weight). A primary propensity scoring analysis ignored the weight variable and excluded subjects with missing age or number of previous births. A second propensity score analysis included the weight variable in the propensity score calculation after excluding all subjects with missing baseline information.

\section{Results}

A total of 799 pregnant women were admitted to L \& D during the 90 -day study period. 166 patients were excluded due to scheduled cesarean section and 633 subjects met initial inclusion criteria. Of these 633 subjects, 227 patients who reached full dilation chose to receive the intervention. 273 patients who reached full dilation declined to use the perianal stabilization device but agreed to allow their outcomes to be used as the control group. Descriptive and outcome data for the 133 women who were eligible on admission but did not reach $8-10 \mathrm{~cm}$ dilation were not retained by the study personnel at the site.

Table 1 shows the distribution of the pre-delivery factors in the data set including weight, prior hemorrhoids, previous C-section, number of previous births, and race. Of these factors, only prior hemorrhoids were statistically significant between the groups (55/227 (24.2\%) perianal stabilizer, $19 / 273(7.0 \%)$ control; $\mathrm{p}<0.001)$. There was a low rate of prior C-Section in the participating patients with $3 / 227(1.3 \%)$ perianal stabilizer and $6 / 273(2.2 \%)$ control having a confirmed prior C-Section.

Table 2 compares variables related to the index labor and delivery in the two groups. Induction of labor and use of an epidural were considered as baseline factors for the propensity scoring analysis. Labor induction was similar in the two groups with 63/227 (27.6\%) perianal stabilizer and 69/273 (25.3\%) among control patients. Placement of an epidural was higher in perianal stabilizer patients (217/227 (95.6\%) than in control patients $(235 / 273(86.6 \%)(\mathrm{p}<0.001)$. Patients utilizing the perianal stabilizer experienced a higher rate of episiotomy $(13.7 \%$ $(31 / 227)$ LaborGuard $^{\text {tw }}$ vs $8.1 \%(22 / 273)$ control, $\left.\mathrm{p}=0.043\right)$ and a higher rate of perianal tears $\left(37.9 \%(86 / 227)\right.$ LaborGuard $^{\mathrm{mw}}$ vs $23.8 \%(65 / 273)$ control, $\mathrm{p}<0.001)$.

Regarding the primary outcome, the C-Section rates were $1.8 \%$ $(4 / 227)$ and $12.8 \%(35 / 273)$ in perianal stabilizer patients and control patients respectively $(\mathrm{p}<0.001)$. The relative risk of a C-Section in perianal stabilizer patients vs. control was $0.14(0.05,0.38)$ which represents an $86 \%$ lower risk of a C-Section in perianal stabilizer patients (Table 3 ).

The propensity scoring analyses were performed using the following factors to model the use of perianal stabilizer in the study population: age, weight, number of previous births, prior hemorrhoids, previous C-Section, induced labor, and use of an epidural. Subjects with missing baseline values were excluded from the propensity score analyses and two models were considered including and excluding baseline weight due to the relatively large proportion of subjects who were missing baseline weight. The propensity scores were used to perform a stratified
Table 1. Comparison of Demographic and Pre-delivery Variables

\begin{tabular}{|c|c|c|c|}
\hline Measure & $\begin{array}{l}\text { Labor Guard }^{\mathrm{TM}} \\
\quad(\mathrm{N}=\mathbf{2 2 7})\end{array}$ & Control (N=273) & P-value \\
\hline Age (years) & & & 0.154 \\
\hline $\mathrm{N}$ & 225 & 268 & \\
\hline Mean (SD) & $28.1(5.64)$ & $28.9(5.92)$ & \\
\hline Median & 28 & 29 & \\
\hline Min, Max & 16,44 & 16,43 & \\
\hline Weight (kg) & & & 0.155 \\
\hline $\mathrm{N}$ & 206 & 252 & \\
\hline Mean (SD) & $80.6(19.24)$ & $83.7(20.57)$ & \\
\hline Median & 77 & 78.5 & \\
\hline Min, Max & 35,200 & 47,220 & \\
\hline Prior Hemorrhoids & & & $<0.001$ \\
\hline Yes & $55(24.2 \%)$ & $19(7.0 \%)$ & \\
\hline No & $172(75.8 \%)$ & $254(93.0 \%)$ & \\
\hline $\mathrm{N}$ & 227 & 273 & \\
\hline Previous C-Section & & & 0.730 \\
\hline Yes & $3(1.3 \%)$ & $6(2.2 \%)$ & \\
\hline No & $219(96.5 \%)$ & $260(95.2 \%)$ & \\
\hline Unknown & $5(2.2 \%)$ & $7(2.6 \%)$ & \\
\hline $\mathrm{N}$ & 227 & 273 & \\
\hline Previous Births & & & 0.110 \\
\hline 0 & $97(43.1 \%)$ & $104(38.1 \%)$ & \\
\hline 1 & $72(32.0 \%)$ & $87(31.9 \%)$ & \\
\hline 2 & $42(18.7 \%)$ & $50(18.3 \%)$ & \\
\hline 3 & $10(4.4 \%)$ & $18(6.6 \%)$ & \\
\hline 4 & $2(0.9 \%)$ & $7(2.6 \%)$ & \\
\hline 5 & $2(0.9 \%)$ & $4(1.5 \%)$ & \\
\hline 6 & $0(0.0 \%)$ & $2(0.7 \%)$ & \\
\hline 10 & $0(0.0 \%)$ & $1(0.4 \%)$ & \\
\hline $\mathrm{N}$ & 225 & 273 & \\
\hline Race & & & 0.507 \\
\hline $\begin{array}{c}\text { African American or } \\
\text { Black }\end{array}$ & $14(6.2 \%)$ & $22(8.1 \%)$ & \\
\hline Asian & $27(11.9 \%)$ & $30(11.0 \%)$ & \\
\hline Caucasian & $130(57.3 \%)$ & $150(55.0 \%)$ & \\
\hline Hispanic & $40(17.6 \%)$ & $54(19.8 \%)$ & \\
\hline Unknown & $14(6.2 \%)$ & $17(6.2 \%)$ & \\
\hline Other & $2(0.9 \%)$ & $0(0.0 \%)$ & \\
\hline $\mathrm{N}$ & 227 & 273 & \\
\hline
\end{tabular}

analysis. Tables 4.1 and 4.2 show the ANOVA results associated with the logistic model factors. In both models, only prior hemorrhoids and placement of an epidural where significant factors.

Tables 5.1 and 5.2 show the distribution of C-Sections by strata, a stratified p-value, and the adjusted relative risk estimates. The results remained significant in both models and the relative risk was slightly higher in the model removing subjects with missing baseline weight. There did not appear to be heterogeneity across the stratum in terms of relationship of C-Section rates between perianal stabilizer and control subjects.

The indication for cesarean section in the intervention and control groups are listed in Table 6. Less than one-percent $(0.9 \%)$ of interventional patients had cesarean births due to failure to progress compared to $9.2 \%$ of control subjects.

The incidence of cesarean delivery among primiparous patients was $4.1 \%$ (4/97) for intervention patients compared to $24.0 \%$ (28/104) for control subjects. This difference was statistically significant (CI $0.17 ; 95$ $\% \mathrm{CI} 0.06,0.48, \mathrm{p}<.001$ ) with an $83 \%$ reduction in the rate of C-Sections. 
Perineal laceration rates were also compared between intervention and control subjects. In subjects who had a vaginal delivery with laceration (Grades I, II, III, and IV), the laceration rate for perianal stabilizer patients was $38.6 \%$ (86/223) compared to $27.1 \%$ (65/238) for control subjects. The difference between the two groups was significant $(\mathrm{p}=0.010)$. Among patients that sustained Grade III and IV perineal lacerations, the intervention group's laceration rate was $1.8 \%(4 / 223)$ compared to $0.8 \%(2 / 238)$ for control subjects. The difference in Grade III and IV laceration rates between the two groups were not significant, $(\mathrm{p}=0.363)$. The frequency and severity of perineal lacerations are shown in Table 7.

Table 2. Index Labor and Delivery Variables

\begin{tabular}{|c|c|c|c|}
\hline Measure & $\begin{array}{l}\text { Labor Guard }{ }^{\mathrm{TM}} \\
\qquad(\mathrm{N}=\mathbf{2 2 7})\end{array}$ & $\begin{array}{l}\text { Control } \\
(\mathrm{N}=273)\end{array}$ & P-value \\
\hline Labor Induced & & & 0.266 \\
\hline Yes & $63(27.6 \%)$ & $69(25.3 \%)$ & \\
\hline No & $159(70.0 \%)$ & $191(70.0 \%)$ & \\
\hline Unknown & $5(2.2 \%)$ & $13(4.8 \%)$ & \\
\hline $\mathrm{N}$ & 227 & 273 & \\
\hline Had Epidural & & & $<0.001$ \\
\hline Yes & $217(95.6 \%)$ & $235(86.1 \%)$ & \\
\hline No & $10(4.4 \%)$ & $38(13.9 \%)$ & \\
\hline $\mathrm{N}$ & 227 & 273 & \\
\hline Had Episiotomy & 1( & & 0.043 \\
\hline Yes & $31(13.7 \%)$ & $22(8.1 \%)$ & \\
\hline No & $196(86.3 \%)$ & $251(91.9 \%)$ & \\
\hline $\mathrm{N}$ & 227 & 273 & \\
\hline Had any Tear & & & $<0.001$ \\
\hline Yes & $86(37.9 \%)$ & $65(23.8 \%)$ & \\
\hline No & $141(62.1 \%)$ & $208(76.2 \%)$ & \\
\hline $\mathrm{N}$ & 227 & 273 & \\
\hline $\begin{array}{l}\text { Hemorrhoids Post- } \\
\text { Delivery }\end{array}$ & & & $<0.001$ \\
\hline Yes & $58(25.6 \%)$ & $36(13.2 \%)$ & \\
\hline No & $169(74.6 \%)$ & $237(74.5 \%)$ & \\
\hline $\mathrm{N}$ & 227 & 273 & \\
\hline
\end{tabular}

Table 3. Primary study outcome: Relative risk of Cesarean Delivery

\begin{tabular}{|c|c|c|c|c|}
\hline $\begin{array}{c}\text { Type of } \\
\text { Delivery }\end{array}$ & $\begin{array}{c}\text { Labor Guard } \\
(\mathbf{N}=\mathbf{2 2 7})\end{array}$ & $\begin{array}{c}\text { Control } \\
\mathbf{( N = 2 7 3 )}\end{array}$ & $\begin{array}{c}\text { Likelihood } \\
\text { Ratio Chi- } \\
\text { Squared Test } \\
\text { P-value }\end{array}$ & $\begin{array}{c}\text { C-Section } \\
\text { Relative Risk } \\
\text { (95\% CI) }\end{array}$ \\
\hline C-Section & $4(1.8 \%)$ & $35(12.8 \%)$ & $<0.001$ & 0.14 \\
\hline Vaginal & $223(98.2 \%)$ & $238(87.2 \%)$ & & 0.05 \\
\hline $\mathrm{N}$ & 227 & 273 & & 0.38 \\
\hline
\end{tabular}

Table 4.1. Primary Propensity Scores Logistic Model ANOVA Between Groups

\begin{tabular}{|c|c|c|c|}
\hline Model Factor & Df & Chi-Square & P-value \\
\hline Age (years) & 1 & 2.41 & 0.121 \\
\hline Prior Hemorrhoids & 1 & 26.70 & $<0.001$ \\
\hline Previous C-Section & 2 & 0.54 & 0.762 \\
\hline Previous Births ${ }^{1}$ & 1 & 3.06 & 0.080 \\
\hline Induced Labor & 2 & 1.02 & 0.601 \\
\hline Epidural $(\mathrm{Y} / \mathrm{N})$ & 1 & 12.04 & $<0.001$ \\
\hline
\end{tabular}

Note: 9 subjects were excluded due to missing data

Note: 2 subjects were missing previous births

7 subjects were missing age
Table 4.2. Primary Propensity Scores Logistic Model ANOVA Between Groups

\begin{tabular}{|c|c|c|c|}
\hline Model Factor & Df & Chi-Square & P-value \\
\hline Age (years) & 1 & 2.03 & 0.154 \\
\hline Weight (kg) & 1 & 2.12 & 0.145 \\
\hline Prior Hemorrhoids & 1 & 24.98 & $<0.001$ \\
\hline Previous C-Section & 2 & 0.22 & 0.898 \\
\hline Previous Births & 1 & 2.56 & 0.109 \\
\hline Induced Labor & 1 & 0.72 & 0.698 \\
\hline Epidural (Y/N) & 1 & 11.44 & $<0.001$ \\
\hline
\end{tabular}

Note: 43 subjects were excluded for missing data: 42 were missing weight, 2 were missing previous births, and 7 were missing age. (Some subjects were missing more than one variable.)

Table 5.1. Primary Propensity Scoring Analysis for C-Section by Perianal Stabilizer Use

\begin{tabular}{|c|c|c|c|c|}
\hline \multirow{2}{*}{ Strata } & \multicolumn{2}{|c|}{$\begin{array}{c}\text { C-Section Rate by Stratum (n/N } \\
(\%))\end{array}$} & \multirow{2}{*}{ P-value $^{1}$} & $\begin{array}{c}\text { C-Section Relative } \\
\text { Risk }^{\mathbf{2}} \mathbf{( 9 5 \%} \text { CI) }\end{array}$ \\
\cline { 2 - 3 } & Labor Guard & Control & & \\
\hline Stratum 1 & $1 / 68(1.5 \%)$ & $6 / 31(19.4 \%)$ & & \\
\hline Stratum 2 & $2 / 47(4.3 \%)$ & $12 / 51(23.5 \%)$ & \multirow{2}{*}{$<0.001$} & \multirow{2}{*}{$0.17(0.07,0.42)$} \\
\hline Stratum 3 & $1 / 47(2.1 \%)$ & $5 / 52(9.6 \%)$ & \\
\hline Stratum 4 & $0 / 41(0.0 \%)$ & $3 / 57(5.3 \%)$ & & \\
\hline Stratum 5 & $0 / 20(0.0 \%)$ & $6 / 77(6.2 \%)$ & & \\
\hline
\end{tabular}

Note: 9 subjects were removed due to missing data: 2 subjects were missing previous births and 7 subjects were missing age.

${ }^{1}$ Cochran-Mantel Haenszel Test General Association Test

${ }^{2}$ Logit-estimate relative risk of C-Section rate in perianal stabilizer patients compared to Control patients.

Table 5.2. Secondary Propensity Scoring Analysis for C-Section by Perianal Stabilizer Use ${ }^{1}$

\begin{tabular}{|c|c|c|c|c|}
\hline \multirow{2}{*}{ Strata } & \multicolumn{2}{|c|}{ C-Section Rate by Stratum (n/N (\%)) } & \multirow[t]{2}{*}{ P-value ${ }^{2}$} & \multirow{2}{*}{$\begin{array}{c}\text { C-Section } \\
\text { Relative Risk } \\
\text { (95\% CI) }\end{array}$} \\
\hline & Labor Guard ${ }^{\mathrm{TM}}$ & Control & & \\
\hline Stratum 1 & $1 / 63(1.6 \%)$ & $6 / 29(20.7 \%)$ & \multirow{5}{*}{$<0.001$} & \multirow{5}{*}{$\begin{array}{c}0.21 \\
(0.08,0.53)\end{array}$} \\
\hline Stratum 2 & $2 / 44(4.4 \%)$ & $7 / 44(15.6 \%)$ & & \\
\hline Stratum 3 & $0 / 41(2.2 \%)$ & $3 / 51(5.9 \%)$ & & \\
\hline Stratum 4 & $1 / 35(2.9 \%)$ & $6 / 56(10.7 \%)$ & & \\
\hline Stratum 5 & $0 / 20(0.0 \%)$ & $5 / 71(7.0 \%)$ & & \\
\hline
\end{tabular}

${ }^{1}$ Note: 43 subjects were excluded for missing data: 42 were missing weight, 2 were missing previous births, and 7 were missing age. Some subjects were missing more than one variable.

${ }^{2}$ Cochran-Mantel Haenszel Test General Association Test

${ }^{3}$ Logit-estimate risk of C-Section rate in perianal stabilizer patients compared to Control patients.

Table 6. Indication for Cesarean Sections

\begin{tabular}{|c|c|c|}
\hline Indication & $\begin{array}{c}\text { Labor Guard } \\
(\mathbf{n = 2 2 7})\end{array}$ & Control (n=273) \\
\hline $\begin{array}{c}\text { Failure to progress (includes arrest of } \\
\text { dilation and failure to descend) }\end{array}$ & $2(0.9 \%)$ & $25(9.2 \%)$ \\
\hline $\begin{array}{c}\text { Non-reassuring FHR (fetal heart rate) } \\
\text { Fetal mal-presentation including breech, } \\
\text { cord or compound }\end{array}$ & 0 & $4(1.4 \%)$ \\
\hline Other clinical indications & $2(0.9 \%)$ & $2(0.7 \%)$ \\
\hline Total & $4(1.8 \%)$ & $6(2.1 \%)$ \\
\hline
\end{tabular}

Note: Cells contain number of cesarean deliveries ( $\%$ of total deliveries in the cohort)

Table 7. Frequency of Perianal Lacerations by Severity in Vaginal Delivery Subjects

\begin{tabular}{|c|c|c|}
\hline Grade of Laceration & Labor Guard $^{\mathbf{T M}}(\mathbf{n}=\mathbf{2 2 3})$ & Control $(\mathbf{n}=\mathbf{2 3 8})$ \\
\hline Grade I & $39(17.5 \%)$ & $36(15.1 \%)$ \\
\hline Grade II & $43(19.3 \%)$ & $27(11.3 \%)$ \\
\hline Grade III & $3(1.3 \%)$ & $1(0.42 \%)$ \\
\hline Grade IV & $1(0.45 \%)$ & $1(0.42 \%)$ \\
\hline Total & 80 & $60(25.2 \%)$ \\
\hline
\end{tabular}

Note: Data is expressed as $\mathrm{n}(\%$ incidence within the cohort) 


\section{Discussion}

A previous prospective randomized study found that the perianal stabilizer device appeared to reduce the incidence of cesarean delivery rates among patients that reached full dilation. In that study, the sample sizes were smaller and involved only one obstetric provider. The goal of this study was to validate the findings in a larger sample and a more "naturalistic" setting involving multiple providers and allowing patients to self-select use of the perianal stabilization device.

Compared to the previous RCT, strengths of this study include: a larger sample size, improved study design, and a community hospital with multiple obstetric providers.

This study has several weaknesses. The non-randomized design is one aspect of the study that reduces its ability to minimize bias. Secondly, the failure to capture baseline and delivery data on the women who chose not to participate interferes with the ability to assess whether there was selection bias in terms of the subjects who did or didn't choose to participate. Although not statistically significant, there could be some concern about the minor increase in perineal lacerations. More study will be required to investigate this. Another concern is the relatively low $\mathrm{C}$-section rate of the control group which is not typical of most obstetric units in the United States.

\section{Conclusion}

In this prospective, non-randomized cohort study, the use of the perianal stabilizer during the second stage of labor was associated with a clinically and statistically significant decrease in the risk of cesarean section from $13 \%$ to $2 \%$. The relative risk of cesarean section in the cohort that chose to use the perianal stabilizer was 0.14 or an $86 \%$ reduction. The number needed to treat (NNT) to avert one cesarean section among women who reach the second stage of labor was 9 .

\section{Authorship and contributorship}

VRB initiated, designed, and participated in the clinical study, as well as drafted the first copy of the manuscript. DP helped train physicians and L\&D staff, was responsible for data collection, and contributed to the manuscript's revision. SRB contributed to the study's design, data analysis, and assisted with the manuscript's revision.

\section{Acknowledgements}

Abraham Morse, MD, MBA - Tufts Medical Center, Boston, USA, Women and Children's Medical Center, Guangzhou, China, provided study analysis advice and extensively revised the final manuscript.

George DeMuth, MPH - Stat One, LLC, Wilmington, NC, USA, provided statistical advice and analysis.

Dignity Health - St. Rose Dominican, Siena Campus, Henderson, Nevada

\section{Funding information}

Stetrix, Inc. provided the Labor Guard ${ }^{\text {tix }}$ perianal stabilizer devices at no cost for this study and provided research support personnel who were responsible for recruitment and data collection but had no role in the design, data analysis or manuscript creation.

\section{References}

1. Martin JA, Hamilton BE, Osterman MJ, Driscoll AK (2019) Births: Final Data for 2018. Natl Vital Stat Rep 68: 13.

2. https://hcupnet.ahrq.gov. Accessed 24 March, 2020.

3. Guise JM, Eden K, Emeis C, Denman MA, Marshall N, et al. (2010) Vaginal Birth After Cesarean: New Insights. Evid Rep Technol Assess (Full Rep) 1-397. [Crossref]

Copyright: (C2020 Bohman VR. This is an open-access article distributed under the terms of the Creative Commons Attribution License, which permits unrestricted use, distribution, and reproduction in any medium, provided the original author and source are credited. 